\title{
Exploring Non-Native EFL Teachers' Knowledge Base: Practices and Perceptions
}

\author{
Anchalee Jansem \\ Department of Western Languages, Faculty of Humanities, \\ Srinakharinwirot University \\ Sukhumvit 23, Bangkok 10110 THAILAND \\ E-mail: anchalee2000@hotmail.com; anchalej@swu.ac.th
}

Received: 07-06-2014

doi:10.7575/aiac.ijalel.v.3n.6p.252
Accepted: 04-08-2014

Published: 01-11-2014

URL: http://dx.doi.org/10.7575/aiac.ijalel.v.3n.6p.252

\begin{abstract}
This qualitative study was conducted to explore non-native EFL teachers' knowledge base performed during instruction, perceived knowledge base underlying teaching practices, and perceived pathways of knowledge base construction. The data from four sources including video recordings of classroom observations, interviews, detailed field-notes taken during classroom observations, and participants' reflections revealed that the eight participants integrated knowledge of the English language, other content areas, instructional delivery, classroom management, and the changing world and social contexts in their instruction. The findings indicated that the participants realized that their knowledge consisted of language construction and skills, other content areas, ability to teach, understanding students' strengths, weaknesses, and needs, the changing world, social contexts, and technology, as well as problem solving ability. Also, they perceived teacher education programs, additional learning experience, teaching experience, in-service professional development activities, and a working environment as key sources of knowledge base construction for non-native teachers.
\end{abstract}

Keywords: knowledge base, English as a Foreign language teachers, knowledge construction

\section{Introduction}

Over the past two decades, after Shulman (1987) discussed the concept of professional teachers, teachers' knowledge base has shed light on studies in the field of education. In accordance with his concept, research in teacher education has shown, for example, the overall picture of teacher knowledge, specific areas of knowledge, and sources of accumulated knowledge. The knowledge base revealed by researchers and teacher educators has broadened an array of what teachers in all subject areas know and are supposed to know. Additional research findings on teacher knowledge provide valuable information essential for both educating and developing teachers. In the field of second language teacher education, a better understanding of teacher knowledge has been recognized. As Richards (2008) notes, second language teacher education is a relatively new discipline as it is perceived as an educational specialization. To professionalize this field, a way to understand the meaning of the profession is needed. That is, investigating what teachers do, think, and believe can fulfill both theory and practice in second language teacher education. Perhaps research that provides this field with findings related to the nature of teachers' knowledge base would be considered a key basis for developing second/foreign language teacher education.

\section{Literature Review}

Shulman (1987) introduced categories of knowledge base that includes content knowledge, general pedagogical knowledge, curriculum knowledge, pedagogical content knowledge, knowledge of learners, knowledge of educational contexts, and that of educational ends, purposes, and values. Among these categories, Shulman emphasizes pedagogical content knowledge, explaining that this subset of knowledge represents the sphere where other categories interweave. Since then, teachers' knowledge base has been mentioned in both teacher education programs and research.

Meanwhile, the term 'knowledge base' has been adopted with slightly different emphases in research. For example, Richards and Farrell (2005) use the term knowledge base as a combination of knowledge and thinking. In forming a knowledge base, second language teachers blend personal with practical knowledge underlying their immediate professional lives. When planning instructional actions, teachers manipulate practical, subject matter, and their personal knowledge (Connelly et al., 1997). That is, content area knowledge an individual teacher received from a teacher education program interacts with their direct experience (Canagarajah, 2005). Similarly, language teachers weave knowledge about the language with their personal involvement, and teaching contexts that range based on curricula for different learners (Mann, 2005). Woven knowledge displayed during instruction is also perceived as pedagogical knowledge. As Mullock (2006) posits, pedagogical knowledge "is accumulated knowledge about the act of teaching, including the goals, procedures, and strategies that form the basis for what teachers do in the classroom" (p. 
48). In addition to practical knowledge, teacher cognition is another term used to discuss what knowledge teachers possess. However, teacher cognition tends to cover an 'unobservable cognitive dimension' regarding what 'teachers know, believe, and think' which is more significant than what teachers do (Borg, 2003, p. 81). In short, teacher cognition reflects the complexity of the wholeness of a teacher's life. Also, their experience as learners and as students in teacher education programs has effects on the teachers' cognition. Instead of being stable, teacher cognition shapes and reshapes itself as a result of the dynamic nature of knowledge and contexts. In between the terms 'pedagogical knowledge' and 'teacher cognition' lies the term 'practical knowledge'. Practical knowledge strongly influences and shapes teaching activities as it consists of the cross between declarative and procedural knowledge, values, beliefs, and reasons (Chou, 2008). Practical knowledge emphasizes the knowledge of rather than for teachers (Fenstermacher, 1994). In teaching, practical knowledge plays significant roles in leading teachers to generate overall knowledge, experiences, and reflections on teaching experiences.

In the field of second language in particular, Richards, (1998) proposed six areas of required knowledge: theories of teaching, teaching skills, communication skills and language proficiency, subject matter knowledge, pedagogical reasoning and decision making, and contextual knowledge. Later, Gatbonton (1999) investigated experienced ESL teachers' pedagogical knowledge. Via the stimulated recall technique, all teachers in her study declared that, during their teaching, they mainly dealt with language management, thoughts about students, the smooth transition of classroom activities, and assessment. Replicating Gatbonton's research, Mullock (2006) studied the pedagogical knowledge base of four teachers and found seven domains of knowledge underlying teaching actions. These included handling language items, factoring in student contributions, determining the contents of teaching, facilitating the instructional flow, building rapport, monitoring student progress, and institutional factors. Mullock's findings were more detailed than Salvatori \& MacFarlan's (2009) which classified necessary knowledge for teachers into only language proficiency, cultural competency, and pedagogical skills.

In EFL contexts, due to the limited number of native speakers, teachers whose first language is other than English constitute the majority in this profession. To ensure effective teaching, teachers are expected to have knowledge of the subject matter, pedagogy, students, classroom learning environment, curriculum, and self (Abdelhafez, 2010). However, compared to native speakers, through the native-nonnative dichotomy, nonnative teachers seem to face challenges regarding accent and credibility (Matsuda \& Matsuda, 2001). Despite some degree of inferiority to native speakers, qualified non-native teachers are considered ideal teachers on the basis that they have had direct experience as additional language learners (Ma, 2012). Learning experience involves using learning strategies that tends to enable them to have an awareness of linguistic, cultural, and learning development. In addition, first-hand experience allows non-native teachers to be concerned with language teaching and learning processes (Ma, 2012; Matsuda \& Matsuda, 2001). This concern enables teachers to remind themselves of, for example, which teaching or learning activities are likely to be effective or ineffective.

However, studies on non-native EFL teachers' knowledge base are scarce. Only a few have explicitly investigated nonnative teachers in EFL contexts. Among these few, Chan (2008) explored elementary Taiwanese in-service EFL teachers' practical knowledge and concluded that their teaching practices were mainly shaped by the orientation of the communicative approach. In doing this, the teachers emphasized oral practice, communicative activities, and scaffolding student learning. Due to limited number of studies on non-native EFL teachers' knowledge base, research on this topic would help supplement findings specifically related to the field of language education.

This study, therefore, was conducted to explore in more depth and to reveal (1) non-native EFL teachers' knowledge base during instruction, (2) knowledge base perceived by non-native EFL teachers, and (3) the pathways of non-native EFL teachers' knowledge construction.

\section{Method}

In accordance with qualitative research, especially the exploratory design, the methods utilized in this study aimed to discover temporal, naturalistic realities in immediate contexts. Instead of pinpointing universal truths, each step of the analytical process was employed to both uncover and refine existing realities. The methodological procedures, therefore, included classroom observations, semi-structured interviews, and content analysis. All of these methods conformed to the concept of triangulation and systematic exploration of this qualitative research on teachers' knowledge base.

\subsection{Participants}

Eight secondary school teachers of English with at least 4 years of teaching experience agreed to participate in this study. Being native speakers of Thai, all eight teachers are classified as non-native speakers of English teaching English as a foreign language. They all majored in either English or English Education. The participants, identified by pseudonyms, were initially recruited via purposive sampling and later finalized in this study voluntarily. The participants' background information gathered prior to the beginning of data collection period is as follows: 


\begin{tabular}{llllll}
\hline Name & Gender & $\begin{array}{l}\text { Years of Teaching } \\
\text { Experience }\end{array}$ & $\begin{array}{l}\text { Grade Levels of } \\
\text { Students }\end{array}$ & Education/Degree \\
\hline Aekachart & Male & 9 & 12 & B.A. \& M.Ed \\
Thansa & Female & 4 & 12 & B.A. \\
Chutha & Female & 30 & $11 \& 12$ & B.A. \& M.Ed \\
Pracha & Male & 6 & $10 \& 12$ & B.Ed \\
Pruksa & Female & 4 & 11 & B.Ed \\
Kumarat & Female & 31 & 11 & B.Ed \\
Jeera & Female & 27 & $7 \& 8$ & B.Ed \\
Ramrat & Male & 11 & $9 \& 10$ & B. A. \&M.Ed \\
\hline
\end{tabular}

\subsection{Data Collection}

To emphasize the trustworthiness of this qualitative study, the notion of triangulation overarched data collection. Triangulation in the study involved collecting data from four sources: (1) a video recording of each participant's two teaching sessions, (2) a video recording of each participant's two interviews, (3) detailed field-notes taken during classroom observations, and (4) participants' reflections.

Each participant was observed and videotaped twice. One week after each observation and videotape review, the researcher visited each participant to conduct a semi-structured interview. The guided interview questions included:

1. When teaching, what knowledge do you employ and how do you employ it?;

2. If asked to describe your knowledge, what do you think it consists of?

3. How do you know that you have knowledge?

4. How have you accumulated your knowledge?

In addition, throughout the data collection period, all participants were encouraged to share their reflections with the researcher via electronic communication including electronic mails and Facebook. The data collection period lasted 6 months in total.

\subsection{Data Analysis}

The analysis of this study was based on grounded theory (Strauss \& Corbin, 1998), with Shulman's concept of knowledge base as a conceptual framework instead of any fixed pre-determined categories. With rich data from multiple sources, data analysis procedures began with transcribing all video recordings followed by categorizing and labeling chunks of data via open-coding. The labels were later grouped and distilled through axial coding to yield finalized data that represented the teachers' knowledge base. The same procedures were applied for analyzing data in the form of interview responses, reflections and field-notes.

\section{Findings}

The analyzed data were organized into three major themes: knowledge and teaching practices, perceived and realized knowledge, and pathways of knowledge construction. Some key attributes in the first two themes may have overlapped. They are presented as the data yielded.

\subsection{Knowledge and Teaching Practices}

In every observed class, the teacher's knowledge facilitated the flow of the lesson. Captured teaching practices in all lessons were in the form of woven knowledge. That is, participants orchestrated and displayed five features of knowledge, varied by the rhythm and flexibility of teaching moments, in all 16 teaching episodes as follows:

\subsubsection{Knowledge of the English language}

The teachers explicitly engaged themselves and students in the exchange game of the English language. In doing this, all teachers treated grammatical rules and vocabulary as something that students were required to encounter, acquire, memorize, and store. For example, Aekachart explained the usage of adjective clauses, "Adjective clauses give details of what kind and which one." Then he presented an example, "Slate which is dense metamorphic rock can be used as patio flooring."

Grammar seemed to be a core part of every lesson. It is not surprising that in all observed classes, there was always room for lecturing or discussing grammar. For example, Thansa directly explained how to form conditional sentences. Her explanation was smoothened by her sequential questions to elicit students' responses. For instance, she asked, "What is the structure of the second type of a conditional sentence?" Then she added examples to ensure that all students understood both the structure and inferred meaning of a particular type of conditional sentences.

In addition to grammar, all teachers considered teaching vocabulary essential in EFL contexts. With a solid understanding of grammar and vocabulary, students were believed to 'get substance' from learning EFL. That is, 
teachers' knowledge of vocabulary was shared with students in all sessions. Embedded with vocabulary teaching was the native speakers' culture. In doing this, all teachers added concepts of culture related to target vocabulary. Knowledge of English skills was another feature explicitly displayed in all participants' instruction. For example, how to write a topic sentence, how to pronounce multi-syllable words, and how to identify the main idea of a reading text represented the teachers' content knowledge. In short, the participants integrated knowledge of English in their teaching.

\subsubsection{Knowledge of other content areas}

At some point, teaching a foreign language was proved to be accompanied by knowledge of other subject areas. During the flow of instructional activities, teachers integrated brief concepts of any related content areas. For example, in a reading comprehension lesson, while explaining the root of the word symbiosis, Pracha asked, "How are an ostrich and a zebra dependent on each other based on symbiosis?" Following a few students' guesses was his explanation that each animal has deficiencies regarding senses. That is, an ostrich has smelling and hearing weaknesses while a zebra has visual deficits. Pracha's supplementary comments included his knowledge of science especially regarding animals.

\subsubsection{Instructional delivery}

All teaching episodes displayed planned instruction that was aimed at student learning. Lead-in techniques, studentteacher interaction, the teacher' presentation, student practice, and the closure respectively were evident in all classroom observations. Though observed lessons varied in terms of instructional methods, strategies, and techniques, teachers seemed to arrange their teaching procedures in accordance with lesson objectives. While Pruksa preferred to employ cooperative learning in her reading lessons, Thansa engaged her students in direct instruction integrated with discussion at the last stage when teaching grammar. Different from other participants, Ramrat was skillful in keeping his students busy doing information gap activities followed by error analyses. In short, all participants consciously employed their selected teaching methods to deliver lessons.

\subsubsection{Classroom management}

Another feature that was evident in all observed classes was knowledge of classroom management. Participants implemented this feature of knowledge even before students entered classrooms. Greeting students, checking their attendance, and delivering lessons reflected participants' understanding of how to manage class based on principles of keeping classrooms orderly. For example, Chutha reminded her students once she put her belongings on the teacher's desk that they were ready to study. Similarly, Aekachart was prepared in the classroom by the time his students got there. Realizing students tended to be tired from walking from building to building due to the school's classroom allocation policy, he told students to take a 1-minute rest. He always made an announcement that he respected students who respected the 'learning community' to which everyone belonged. Classroom management knowledge was seen to overarch the interaction of all agents in each classroom. Techniques parallel to language instruction mainly included with-it-ness, overlapping-ness, and authoritativeness. Spotting student behaviors, dealing with immediate problems, and keeping teaching on track always took place at the same time. In short, exercising teacher power rhythmically underlay the environment in the classrooms. As Kumarat expressed in both an interview and her journal, managing the classroom to ensure the momentum and the flow of learning activities is a prerequisite task for teachers. In particular, activity-based language learning and teaching predominated her instruction. She had to pay extra attention to classroom management in order to smoothen the activities.

\subsubsection{Knowledge of the changing world and social contexts}

Regarding teaching and learning a foreign language as a door to reach unlimited information, participants in this study always expressed their knowledge of social contexts embedded in lessons. At times, discussing what was going on around the world took place in the lesson delivery. For example, during a reading comprehension lesson, Pracha asked, "What does AEC stand for?" He then discussed the necessity for an understanding of the new trend of the ASEAN Community. Other teachers also integrated knowledge of the current issues in their teaching, ranging from internal political conflicts to the rapid movement of technology.

\subsection{Perceived Knowledge}

All participants tended to be conscious in both possessing and displaying their knowledge listed in the previous section. Viewing themselves as non-native English teachers, these teachers regarded knowledge base as essential. Lacking even one type of knowledge would obscure their teaching practices. However, instead of assessing the strength and weakness of their knowledge, the teachers seemed to reflect on what they knew. The types of knowledge base that participants realized they possessed are as follows:

\subsubsection{Language construction and skills}

The participants realized that the very basis for teaching English as a foreign language was knowledge of the construction and elements of the language. However, an understanding of the English language cannot be compared to that of native speakers. What they believed was necessary for them to possess was 'non-native teachers' sufficient knowledge of the target language. They used the word 'sufficient' instead of 'native-like proficiency'. As non-native teachers, knowledge of grammar, vocabulary, and pronunciation was the pillar for being teachers. As Kumarat said, "In every lesson, you teach grammar, vocabulary, and pronunciation. Without this preliminary knowledge, you cannot teach." Most participants were certain that what they knew enabled them to carry out the teaching, but some questioned themselves in terms of language skills, especially speaking. 


\subsubsection{Knowledge of other content areas}

In addition to knowledge of the English language, that of other subject areas significantly benefits teachers. In interviews, Jeera and Ramrat explicitly noted that teachers must be knowledgeable in everything in order not to struggle when discussing the content embedded in texts. Supplementary knowledge includes cultures of native speakers, social studies, and even art and music. This extra knowledge can enhance EFL teachers to be skillful in explaining related concepts when explaining vocabulary and idioms.

\subsubsection{Ability to teach}

Considering their knowledge base, all participants proudly said that their abilities to teach either met or exceeded career requirements. Among all types or features of knowledge, what made them perceive themselves as 'teachers' was the ability to carry out teaching practices. Without this ability, teaching could not take place. Being non-native speakers of English did not affect their teaching. Multiple roles they played in the classroom were interwoven by elements of knowledge of how to teach rather than nonnativeness. Among these, how to manage content to help students learn outperformed any other elements. Likewise, being a non-native speaker in this context tends to be well-rounded, due to being English language learners themselves. In doing this, all participants believed that they did a better job, especially sharing their learning strategies.

\subsubsection{Understanding students' strengths, weaknesses, and needs}

To complete teaching, an understanding of what students need, what they are good at, and what they are weak in is compulsory. As Kumarat wrote in her journal,

How I teach depends on students. It would be a lot easier if my students had

similar likes, dislikes, and abilities. But they absolutely do not. When I plan a

lesson, details about my students are my first concern.

Aekachart also mentioned the importance of knowing students. He said, "Students' interests and needs guide my teaching. Actually I prefer lectures. But when I realize my students' preferences, I know I have to do what they prefer." In addition, what students lack was another concern the participants took into account, both when designing and also teaching the lessons. Hence, adjustment was always inevitable.

\subsubsection{Knowledge of the changing world, social contexts, and technology}

Knowing what was going on, both internationally and locally, was another dimension of knowledge underlying teaching. As Chuta said, "Know ledge of pedagogy alone is not sufficient for being a teacher. Teaching English now requires knowledge of everything ranging from the business and entertainment industries to technology and sports. And the rapid advancement of technology has pushed me to worry about technological literacy. If not, teachers would be far behind students." Classrooms can be viewed as represented units of social contexts. To help teachers understand students, they needed to keep up with all dimensions of the larger social contexts. Supporting this idea, Pracha said, "I am teaching a course on research and language use. How can I teach the course unless I am knowledgeable and up-todate enough to integrate social innovation in my lessons?"

\subsubsection{Problem solving ability}

Teaching is not a straightforward task. Rather, it is complicated due to its multi-faceted nature. Although some of teaching constraints are predictable, most are not. And the unpredictability requires a skillful problem-solving ability. All participants encountered a variety of problems including, particularly, students' behavior, attitudes toward English, and extremely low learning performance. Demanding parents and pressure from assurance measurement worsened teaching. To deal with these, or at least to lessen them, teachers had to possess problem solving knowledge. Pruksa noted in an on-line chat that she had just realized that problem solving had to be available at all times. As the majority of her students tended to be off-task, and even misbehaved at times, she had to address these issues, utilizing appropriate classroom management techniques. In terms of students' difficulties in learning English, problem solving stemmed from analyzing the causes followed by using intervention to reduce the problems. In doing this, Kumarat changed her teaching strategies.

\subsection{Pathways of Knowledge Base Construction}

Regarding constructing knowledge base, the participants reflected upon situations and sources they believed helped them accumulate knowledge they had. Gaining knowledge does not take place promptly. Instead, constructing knowledge tends to be a complicated process involving multiple pathways of teachers' lives. The following is the pathways of knowledge construction shared by all 8 participants.

\subsubsection{Teacher education programs}

The first formal experience that directly led teachers to construct knowledge for being English teachers was studying in their undergraduate programs. Among the eight participants, four graduated from the Faculty of Education while the others majored in English offered by either the Faculty of Arts or the Faculty of Humanities. The former believed that they had been prepared as teacher candidates required to blend all necessary qualities of effective teachers with an emphasis on learning how to teach. The latter constructed content knowledge of the English language. For those who furthered their studies and had a Master's Degree in teaching English, additional experience gained from their graduate studies provided them with pedagogical content knowledge. As Aekachart said, "Studying toward a Master's degree 
deepened my understanding of language teaching theories I had never known before." In short, the participants perceived knowledge of English and pedagogical skills as the very foundation of the knowledge base introduced to them when attending teacher education programs, either at the undergraduate level or graduate levels, or both.

\subsubsection{Additional learning experience}

Since all participants became teachers, their career can be viewed as different forms and moments of learning. For example, to Pruksa, sharing ideas about teaching with senior colleagues helped her learn a lot. In terms of the knowledge of English as a foreign language, they accepted that learning English was part of their lives. Learning took place when participants had motivation and desire to improve themselves. Additional learning, in this regard, therefore, was a form of informal learning of one's choice. For example, observing colleagues' classrooms and discussing any issues related to current issues in English teaching also shared the meaning of learning experience. Reading textbooks and any materials in the field of teaching and learning was also perceived as learning experience. In short, learning experience in this regard refers to any self-selected activities in which each teacher was engaged that led to knowledge and skills growth as an English teacher.

\subsubsection{Teaching experience}

To gradually strengthen the knowledge base, all participants stated that teaching experience played a significant role. Teaching and learning took place concurrently. As Pracha said, "Teaching is learning. The longer I teach the more I learn." That is, teaching generated the whole spectrum of existing knowledge. For example, the first year of teaching overwhelmingly challenged Jeera. Having been teaching for 27 years, in contrast, equipped her with knowledge and skills to deal with classroom management and teaching methodologies. Teaching experience was in the form of being both successful and unsuccessful. Yet, trial and error always enhanced knowledge growth. Similarly, Ramrat proudly expressed his viewpoints that his 11 years of teaching experience enabled him to be a 'master teacher'. So, it was time for him to share knowledge with other teachers in the teaching community of English teachers at the national level. Without a number of years of teaching experience, he was uncertain if he would be as confident as he was.

\subsubsection{In-service professional development}

Knowledge growth, especially which is related to instructional methods and language construction was significant due to attending professional development sessions at least three times a year. Workshops, seminars, and short courses provided by either universities or educational supervisory units enabled participants to keep up with current trends in English teaching practices. Examples of what they got from professional development activities included using language games, innovative teaching tips, and testing. Although the depth and emphases seemed to vary, what introduced to them could be weaved in their teaching. As Ramrat wrote in his Facebook message, "Today I tried using a guessing game for teaching speaking I got from last week's ERIC workshop. Students were enthusiastic, and I believe that they love learning English via games."

\subsubsection{Working environments}

Another point in the pathway that influenced the construction of a knowledge base for language teachers is the working environment. Once a participant started his/her teaching career, s/he has been a member of a community that has affected who s/he was and how s/he changed. All components, ranging from colleagues, administration, students, school resources, curriculum implementation, and parents to the culture of the organization, of each school tend to be a significant variable for change. In terms of colleagues, Pruksa said that working with veteran teachers implicitly pushed her toward self-improvement, particularly in regard to knowledge of the English language. English-speaking colleagues not only promoted conversational exchanges forcing participants to converse in English, but also served as resources for checking appropriate language use. In addition to colleagues, students were inevitable factors that pushed participants to seek professional growth. While teaching high-achieving students energized participants to broaden English and pedagogical knowledge, dealing with low-achieving ones challenged them to search for innovative teaching techniques. Other factors including effective administration, sufficient resources, sound curriculum, and supportive parents affected the participants' knowledge base. For example, the curriculum implemented at Aekachart's school required him to adopt content-based courses that, in the meantime, let him utilize content-based instructional methods and materials. In doing this, he integrated all types of knowledge to carry out teaching, resulting in implicit knowledge growth.

\section{Discussion}

The findings in this study have shown intriguing aspects of eight participants' knowledge base. All aspects contribute to the brief discussion of three major points in the field of language teacher education with a focus on knowledge base.

Firstly, knowledge base explicitly expressed in teaching practices and underlying the participants' behavior as well as thoughts is consistent with Shulman's concept. Content knowledge revealed in this study was in the form of knowledge of the English language, both language elements and skills. General pedagogical knowledge was mainly applied through classroom management. Pedagogical content knowledge was represented via instructional delivery or the ability to teach. Knowledge of learners was situated in understanding students' strengths, weaknesses, and needs. However, the intensity of the congruence of curriculum knowledge, knowledge of educational contexts, ends, purposes, and values seemed to be transformed via other overlapping attributes. That is, knowledge of content areas, the changing world, and social contexts shed light on participants' realization that in the meantime shaped the way they carried out teaching roles. It is interesting to note that participants viewed problem solving, not listed in Shulman's categories, as 
part of their knowledge. This unmatched knowledge format is not surprising. As Shulman (1987) notes, for teachers, a knowledge base is neither 'fixed' nor 'final' (p. 12). This aspect confirmed his remark that a knowledge base is open to be discovered and refined.

Secondly, the findings indicated that teachers' knowledge base represented the overall sphere of teaching rather than the strict indicators of instructional competencies (Connelly et al., 1997). As indicated in the findings, personal practical knowledge always existed. That is, for example, self-created teaching techniques seemed to depend on each participant's beliefs and justification. Also, each of them blended their personal background with individual characteristics of being a teacher (Clandinin, 2013). In this case, participants themselves connected all related variables, such as part of theories, students' conditions, and their additional learning experience, when delivering instruction. In other words, the perception of 'self' and the realization of knowledge mutually shaped teaching practices.

Lastly, the label 'nonnative speaker' did not affect the way participants accumulated and perceived knowledge. It is likely that EFL contexts were perceived as a unique circumstance. Hence, all participants knew who they were instead of comparing themselves with native speakers. The perception resulted in the way each of them figured out how she or he could apply knowledge, both as a teacher and a foreign language learner. This viewpoint supports Philipson's (1996) and Medgyes's (1996) argument that nonnative teachers can be qualified teachers when sharing experience and language learning strategies with students to benefit both teaching and learning. And the acts of teaching performed inevitable represent their knowledge base.

\section{Conclusions and Implication}

The findings reflect specific aspects of nonnative EFL teachers' knowledge base, particularly the elements of knowledge underlying teaching practices and the pathways of knowledge formation. For language teacher educators, these findings can provide confirmation that teachers elaborate knowledge in their teaching. Yet, the elaboration or knowledge management tends to be flexible, depending upon immediate contexts. And to realize these contexts, teachers integrate a number of factors that in the meantime can be viewed as other elements of knowledge base. Consequently, to implement teacher education programs and professional developments activities, the knowledge base should be taken into account. It is important that teacher educators understand the influence of in-service teachers' knowledge. The study has also contributed to further understandings of teachers' thoughts and professional experience. All of these affect the way they both construct and bring knowledge into teaching practices. Another implication for teacher education may lie in the methods to enable EFL teachers to strengthen their knowledge base, using their knowledge as a baseline. Also, the study provides a springboard for further study of nonnative EFL teachers with particular reference to an understanding of the complexity of knowledge construction and implementation. Further research can utilize ethnographic methods to uncover these aspects in detail.

\section{References}

Abdelhafez, A. (2010). An investigation into professional practical knowledge of EFL experienced teachers in Egypt: Implications for pre-service and in-service teacher learning (Doctoral Dissertation). Retrieved from

https://ore.exeter.ac.uk/repository/bitstream/handle/10036/119325/AbdelhafezA.pdf?sequence=2

Borg, S. (2003). Teacher Cognition in Language Teaching: A review of research on what language teachers think, know, believe, and do. Language Teaching, 36, 81-109.

Canagarajah, A. S. (Ed.) (2005). Reclaiming the local in language policy and practice. Mahwah, NJ: Lawrence Erlbaum.

Chan, Y.C. (2008). Elementary school EFL teachers' beliefs and practices of multiple assessment. Reflections on English Language Teaching, 7(1), 37-62.

Chou, C. (2008). Exploring elementary English teachers' practical knowledge: A case study of EFL teachers in Taiwan. Asia Pacific Education Review, 9, 529-541.

Clandinin, D. J. (2013).Personal Practical Knowledge: A Study of Teachers' Classroom Images. In C. J. Craig, P. C. Meijer, \& J. Broeckmans (Eds.) From teacher thinking to teachers and teaching: The evolution of a research community (pp. 67-95). Bingley, UK: Emerald Group.

Connelly, M.F., Clandinin, J.D., \& He, M. F. (1997). Teachers' Personal Practical Knowledge on the Professional Knowledge Landscape. Teaching and Teacher Education, 13, 665-674.

Fenstermacher, G. D. ( 1994). The knower and the known: The nature of knowledge in research on teaching. Review of Research on Education, 20, 1-54.

Gatbonton, E. (1999). Investigating experienced ESL teachers' pedagogical knowledge. Modern Language Journal, 83(1), 35-50.

Ma, L, P. (2012). Advantages and Disadvantages of Native- and Nonnative-English-Teachers: Student Perceptions in Hong Kong. TESOL Quarterly, 46(2), 280-305.

Mann, Steve J. (2005) The language teacher’s development. Language Teaching, 38 (3), 103-118. 
Matsuda, A., \& Matsuda, P. K. (2001). Autonomy and collaboration in teacher education: Journal sharing among native and nonnative English-speaking teachers. The CATESOL Journal, 13(1), 109-121.

Medgyes, P. (1996). Native or non-native: Who's worth more? In T. Hedge \& N. Whitney (Eds.), Power, pedagogy \& practice (pp. 31-42). Oxford: Oxford University Press.

Mullock, B. (2006). The Pedagogical Knowledge Base of Four TESOL Teachers. The Modern Language Journal, 90 : 48-66.

Phillipson, R. (1996). ELT: The native speaker's burden. In T. Hedge \& N. Whitney (Eds.), Power, pedagogy \& practice (pp. 23-30). Oxford: Oxford University Press.

Richards, J. C. (2008). Second Language Teacher Education Today. RELC, 39(2), 158-177.

Richards, J. C. (1998). Beyond training: Perspectives on language teacher education. Cambridge, UK: Cambridge University Press.

Richards, J. C., \& Farrell, T.S. (2005). Professional development for language teachers. Cambridge, UK: Cambridge University Press.

Salvatori, M., \& MacFarlane, A. (2009). Profile and pathways: Supports for developing FSL teachers' pedagogical, linguistic, and cultural competencies. Canadian Association of Second Language Teachers. Retrieved from http://www.caslt.org/pdf/en/what-do/caslt- panorama-profilepathways-e.pdf

Shulman, L. (1987). Knowledge and teaching: Foundations of the new reform. Harvard Educational Review, 57(1), 122.

Strauss, A., \& Corbin, J. (1998). Basics of qualitative research: Techniques and procedures for developing grounded theory. Thousand Oaks, CA: Sage. 